\title{
A Review Paper on "Smart Railway Crossing using Microcontroller"
}

\author{
Prof. Sushant M. Gajbhiye \\ Assistant Professor, \\ Dept. of Civil Engineering, \\ Guru Nanak Institute of Technology, \\ Nagpur (MS), India.
}

\author{
Prof. Raju A. Bondre \\ Assistant Professor, \\ Dept. of Civil Engineering, \\ Guru Nanak Institute of Technology, \\ Nagpur (MS), India.
}

\author{
Prof. Zen P. Raut \\ Assistant Professor, \\ Dept. of Civil Engineering, \\ Guru Nanak Institute of Technology, \\ Nagpur (MS), India.
}

\begin{abstract}
The main purpose of this research paper is to reduce the railway accidents occurring at the level crossings (Intersection Points). Railway is the vast mode of the transportations in India and it is the cheapest way for travelling. So there are more numbers of rail users and it is not easy to stop railway anywhere to obstruct accident, due to that there are major drawbacks of that. At present anunmanned system is available at level crossings and hence, lots of accidents occur at such crossings, since there is no one to take responsibility of the functioning of the railway gate when a train reaching the crossing.

The objective of this research paper is to handle and control the system of railway gate by applying the microcontroller. This model includes infrared (IR) sensors, radio frequency indication
\end{abstract}

device (RFID), Liquid Crystal Display (LCD),Light-emitting diode (LED), Lights, buzzer, motor driver and microcontroller. In the self-regulating railway gate control system, at the level crossing the meeting of the train is identify by the IR sensor and RFID placed close to the gate. In case of RFID it identifies only meeting of train. Hence, the time for which it is closed is less compared to the manually operated gates and reduces the human labor. As the whole system is automated fault occurring due to manual operation are restricted because the corrected of automated operation is more than the manned operation. Side sensor activated and the signal about the removal is sent to the microcontroller and motor turns in further direction and gate opens and motor shut down automatically.

Keywords: Intersection point, speed, RFID, crossing width, gate length, LCD.

\section{INTRODUCTION}

Railroad is the generalized transportation which is widely used the world and in Indian, it is the country which has the world biggest railroad system, other than that several rails going on the right track every day. As it is recognizing that it potentially hard to stop the train at every second, so the railroads have given rail line gates to properly being mobilized at the level of intersection. At the intersection point the entryways are close for the avenue movement of the traffic, it is required to land on the right track for that the entryways are opened for the street customers. The degree intersection in India may be isolated into two manners manned and unmanned system and stored an eye on degree of intersection, in which it is protected by means of gatemen as representative of railways.

The gates restrain the street interest with the aid of shutting the entryway on the receipt of drawing close and prepare statistics and manipulate motel through a telephone line. Likewise in this framework the motor motive force acquires a green flag just when the railroad entryways shut. A big part of the level intersection towards railway station kept kept an eye on it.

Unmanned stage intersections are spots, which are unblanketed. On this way a moderate degree of carelessness approaches to road customers activates mischances at such location. It might be worth saying here that the extensive majority of prepare mishaps promoting loss of assets and life took place at unmanned stage intersection. To warning at all the level intersections inside the immeasurable device is used by the Indian railways.

Injuries happened even at stored an eye on stage intersections because of the mistakes submitted by gateman. The Railroads being the least expensive method of transportation are favored over the various methods. Be that as it may, there are such a significant number of mishaps occurring at the kept an eye on control level intersections. This is fundamentally because of the imprudence in manual tasks or absence of laborers. This venture uses two sets of IR sensor and RFID put at the either sides of door. Each pair of sensor comprise of a transmitter and collector, for our situation light discharging diode is utilized as a transmitter and a p-n intersection photodiode is utilized as beneficiary.

It identifies the appearance of the train by the two sides. RFID is likewise utilized for the location of explicit train as it were. RFID comprise of tag per user. Tag is given to the train and it will be perused by that RFID per user as it were. At the point when per user peruses that label which is set on train then the door will be shut. At the point when the last carriage of train passes having labeled then the door will be opened. LCD will show data for the street clients. This procedure lessens the traffic and time for which clients need to for long time at level intersection. 


\section{LITERATURE:}

Barry Jesia G and Harrison James E (2008), he entitled "Series of Injury because of Transport Accidents Involving Railway Train", he analyzedand compared the train accidents, hospitalization keep, etc. It gets in to additional description of statistics. The danger of significant injury, based on distance cosmopolitan, is ten times bigger for passengers travel by automotive compared with passengers travelling by rail. The mean length of keep in hospital for a transport accident involving a railway train was four days that were longer than the mean length of keep for all External causes of injury.

Zuhairi Mahdi Al- Ahmed Salih (2013), the research paper is about "Automatic Railway Gate and crossing control based sensors and microcontroller", he provides some solutions to minimize rail traffic accidents and discusses that this is dangerous than other transportation accidents in terms of severity and death rate etc. Therefore more efforts are necessary for improving safety. There are many Railways crossing which are unmanned due to lack of manpower needed to fulfill the demand. Hence many accidents occur at such crossing since there is no one to take care of the functioning of the railway gate when a train approaches the crossing . The main objectives of this Paper is to manage the control system of railway gate using microcontroller.

Anil M.D.et al (2014), he discussed about "Advanced Railway accident prevention System Using Sensor Network"in that he talk about increased rail traffic density across the world and in such circumstances how to control. This system makes uses of IR sensors, fire sensor, Zigbee and embedded systems which prevent accident. When the train arrival at a distinctive side then transmitter IR sensors create their suitable hint and then at the equal time the receiver IR sensor receives their indication and makes railway into stopping position.

FareeduddinKhajaandReddyAnj (2014), he studied on "Evolution of Urban Transportation Planning with Reference to Hyderabad Metro Rail" the articles gives detailed urban planning of Urban Metro Corridor through GIS system" and there by commuters can travel smoothly. Authors have made an attempt has been made to use geographical information system (GIS) to study one of the three high density corridors of Hyderabad Metro Rail. All the issues related to planning, construction and implementation along with its impact on traffic and environment were addressed. GIS techniques/ maps were used to analyses the study area including location of metro stations and also the effects on surrounding environment, heritage and religious structures etc. Environmental Impact study report was prepared using GIS with reference to land acquisition, loss of green cover the effects on environment during and after construction viz. air quality, noise, vibrations etc. and measures for its mitigation were also suggested. Contour maps were used to know the drainage conditions and it was found that slope is towards Musi River. A detailed report on positive and negative impacts of metro rail was also analyzed. Ramesh S. Et al (2014) explained "Automatic track inspection in railway network", he stresses the reliability on safety Parameters in Indian rail system thereby causing rail accidents. The main problems about railway analysis is detection of crack in the structure this project proposes a cost effective solution to the problem of railway track crack detection utilizing RF control assembly which track the exact location of faulty track which then mended immediately so that many lives will be saved.

M Kiruthigaet al (2014) researched on "Wireless communication system for railway signal automation at unmanned level". He analyzes the accidents at unmanned level crossing and collision of trains running on same track where the accidents are more in railway. Such accidents cause heavy human causality and damage to train. Therefore he proposed to develop full proof system to avoid such accidents. Automatic closure of unmanned gate reduces the time for which the gate is being kept closed and provides safety to the road users by reducing accidents.

Bhosale Amol Ankush (2015) discusses about "Automotive Railway Safety and Control using RF model". Heemphasizes about various control measures such as in case emergency, fire in the bogie etc. Railway accidents are often taking place. There are different reasons of railway accident. Railways being cheapest mode of transportation are preferred over all other means. Rail Accidents are very big economic losses are to be faced. The objective of the author is to avoid railway accidents. This model is designed with the help of microcontroller to avoid accidents.

Karthik Krishnamurthy Monica Bobby, Vidya V, Edwin Baby (2015) he studied on "Sensors based automatic railway gate". He introduces the concept of railway gate automation. To avoid the human error that could occur during operation of gate sensors is being used. Delay in opening and closing of gate by gatekeeper may cause the railway accidents. This paper helps to develop a system which automates gate operation at the level crossing using microcontroller and detect collisions at the level crossing the components which is used for the automation of railway gate are sensors that is infrared sensors. IR sensor detects the radiation to detect the motion of the object surrounding it. This paper concluded that automatic railway gate control system is pointed on the idea of reducing human involvement for closing and opening the railway gate which avoids cars and human from crossing railway tracks. Hence, automating the gate can bring about a ring of surety to controlling the gate.

Pillai Binu B and Singh G.D (2015), his article is on "Scenario of Road Accidents in Kerala and its ILL effects". He analyses detailed study on Road accidents and it's after effects lead to a major economic, social and health problem. It highlights the costs experienced during and after the accidents include hospital expenses, administrative and court expenses, wastage of time and also the cost of intangible consequences like pain, grief and sufferings. This can be compared with Rail accidents where in the cost involved and pain undergone by the victims. In Rail systems several measures has been planned and implemented in our country to control the impact of injuries during Rail accidents but the actual implementation is lacking.

UjjwalKohli , Anmol Agarwal (2016)worked on system in India"Smart unmanned level crossing railway system" . He introduces smart unmanned level crossing system which is economic and automatic .This paper deals with automatic 
railway gate operation. In automatic railway gate at a level crossing replacing the gate operated by the gate keeper, it deals with reduction of time for which the gate is being closed and provide safety to the road users by reducing accidents. By employing the automatic railway gate control at the level crossing the arrival of the train is detected by infrared sensors placed near gate. Error due to manual operation is prevented. In this study the author has placed battery to collect electricity supply from piezoelectric plates then battery connected to main parts of the system that is IR sensors and LED screen timer. The paper deals with the solution of unmanned crossing of our country.

Vishwanatha CR, Vidyashree PV Sujit Kumar (2018).He research on,"Smart railway gate system using internet of things". The author provides some solution to accidents and delay in arrival of train, a gate is placed for controlling the movement of vehicles which require human effort and coordination. Gates are manually operated, error which may give rise while opening and closing of gate and technique is suggested here. This paper introduces a whole new way of automating things. From the expected result automation of railway gate control system is implemented to reduce accident and which allows and avoid vehicles and people from passing the crossing. Automation of crossing gate make easy and secure to control the gate in order to avoid accidents and save time of the road users.

\section{CONCLUSION}

Automatic gate system victimization RFID is that the economical and easy method of reducing the accidents at the extent crossings. This offers associate secure model for the railway track system.

Victimization RFID tag and reader, microcontroller detects solely the arrival of the precise train therefore only at that point gate is open and shut. Because of that there is no any hold up and wastage of your time.
This can scale back the accidents in great quantity. This method will contribute a lot of profit either to the road users or to the railway management. Since the planning is totally machine-controlled it can be employed in remote villages wherever no station master or line man is gift.

The RFID placed at the either facet of gate in order that they will notice the arrival and departure of train. Now a day's automatic system occupies every sector of applications because it is reliable and correct.

\section{REFERENCES}

[1] Ahmed salihMahid. Al-Zuhairi,"Automatic Railway Gate and Crossing Control based Sensors and Microcontroller", International Journal of Computer Trends and Technology (IJCTT) - Volume 4, Issue 7, July 2013.

[2] Anil M.D et.Al. (2014), Advanced Railway Accident Prevention System Using Sensor Networks, International Journal of Advanced Research In Computers And Communication Engineering, ISSN-22781021, Volume - 3, Issue- 5.

[3] Barry Jesia G \& Harrison James E (2018), Series of Injury Due To Transport Accidents Involving Railway Train, 2001-2002 to 20052006, Injury Research Statistics Series Number 43(CAT No. INJCAT), ISSN-1444-3791.

[4] Fred Coleman 3rd, Young J. Moon (2011) Trapped Vehicle Detection System for Four Quadrant Gates in High Speed Rail Corridors Transportation Research Record 1648.

[5] Karthik Krishnamurthy , Monica Bobby Vidya V, Edwin Baby (2015).sensor based automatic railway gate, international journal of advanced research in computer engineering and technology (IJARCET) volume-4, Issue-2, Feb. 20015.

[6] M Kiruthiga et al(2014), Wireless Communication System For Railway Signal Automation At Unmanned Level, International Journal of Innovative Research In Science, Engineering and Technology, ISSN 2319-8753, Volume - 3, Special Issue-1.

[7] UjjwalKohli , Anmol Agarwal (2016),smart unmanned level crossing system in Indian railways research in international journal of recent trends in engineering and research (IJRTER) volume-04, Issue -10, OCT 2016.

[8] VishwanathaCR,vidyashree PV, Sujit Kumar (2018), Smart railway gate system using internet of things (IOT) research in international journal of advance research in computer. Engineering and technology (IJARCET) volume-4, Issue-3, March 2018. 